\title{
EFFECTS OF GENERAL ANAESTHESIA AND SURGERY ON RENAL FUNCTION AND PLASMA ADH LEVELS
}

\author{
H. ISHIHARA, K. ISHIDA, T. OYama, T. Kudo AND M. Kudo
}

IT is WELL KNOWN that intra-operative and post-operative oliguria is associated with alterations in renal function. Furthermore, increased secretion of antidiuretic hormone $(A D H)$ has also been reported to play an important role in this oliguria. We have observed a marked influence of anaesthetics on plasma $\mathrm{ADH}$ concentrations in man' ${ }^{1}$ and the mechanisms of increased ADH release during operations have been discussed by Moran ${ }^{2}$ and Ukai. ${ }^{3}$ However, there has been lack of information on the relationship between renal function and ADH secretion during anaesthesia and surgery. The purpose of this study was to elucidate the role of ADH in intra-operative and post-operative oliguria and to evaluate the contribution of depth of anaest hesia and fluid volume to renal function.

\section{Materials AND Method}

\section{Clinical material}

Forty patients, ranging in age from 22 to 58 years, were studied. All patients underwent abdominal operations and were free from hepatic, renal, endocrine and cardiovascular disease and from electrolyte imbalance. They were divided into the following four groups, each consisting of 10 patients; an ether group (nitrous oxidediethyl-ether), a halothane group (nitrous oxide-halothane), a thiopentone group (nitrous oxide-thiopentone) and a fentanyl group (nitrous oxide-droperidol-fentanyl). The patients were premedicated with pentobarbitone $100 \mathrm{mg}$ orally on the night before operation and again $1 \frac{1}{2}$ hours before the induction of anaesthesia. Meperidine $35 \mathrm{mg}$ and atropine $0.5 \mathrm{mg}$ were given intramuscularly one hour before induction.

Considering diurnal variations in the concentration of plasma $A D H$, induction of anaesthesia started at 8:30 a.m. Induction and maintenance of each group were in the following manner:

Ether group: Anaesthesia was induced with inspired concentrations of diethyl-ether 10 to 20 per cent in nitrous oxide 70 per cent and oxygen

Department of Anaesthesia, Hirosaki University, School of Medicine, Hirosaki, Aomori-ken, Japan, 036.

Canad. Anaesth. Soc. J., vol. 25, no, 4, July 1978
30 per cent and maintained with diethyl-ether combined with nitrous oxide and oxygen $(50 / 50)$.

Halothane group: Anaesthesia was induced with inspired concentrations of halothane 0.5 to 1.5 per cent in nitrous oxide 70 per cent and oxygen 30 per cent and was maintained with halothane 0.5 to 1.5 per cent combined with equal parts of nitrous oxide and oxygen.

Thiopentone group: Anaesthesia was induced with thiopentone 4 to $6 \mathrm{mg} / \mathrm{kg}$ intravenously and was maintained with nitrous oxide 70 per cent and oxygen 30 per cent and incremental doses of thiopentone 50 to $100 \mathrm{mg}$ injected when needed.

Fentanyl group: Anaesthesia was induced with droperidol $0.15 \mathrm{mg} / \mathrm{kg}$ intravenously followed by fentanyl 0.1 to $0.2 \mathrm{mg}$ intravenously combined with nitrous oxide 70 per cent and oxygen 30 per cent, and was maintained with nitrous oxide 70 per cent and oxygen 30 per cent with incremental doses of fentanyl 0.05 to $0.1 \mathrm{mg}$ when needed.

Food and water were withheld for ten hours before induction of anaesthesia. Tracheal intubation was done in all patients upon induction of anaesthesia and was facilitated by intravenous administration of succinylcholine chloride $40 \mathrm{mg}$. Anaesthesia alone was continued for at least 30 minutes before the operation was started. The lungs were ventilated manually throughout the procedure. Adequate muscle relaxation for laparotomy was obtained by intravenous injection of d-tubocurarine $3-6 \mathrm{mg}$ as required. Lactated Ringer's solution $10 \mathrm{ml} / \mathrm{kg} / \mathrm{hr}$ was infused from immediately before induction until the end of the operation. In addition, blood was transfused in the amounts lost when the blood loss was estimated more than $500 \mathrm{~g}$.

For the determinations of plasma concentration of ADH and serum osmolality, $10 \mathrm{ml}$ venous blood samples were taken at the following times: (1) five minutes before induction of anaesthesia, (2) 30 minutes after the start of anaesthesia and before the start of the operation, (3) 10 and 60 minutes after the start of the operation, (4) in the recovery room when the patient had recovered from anaesthesia, (5) on the first, second and third post-operative days, except in thiopentone and fentanyl groups. Urine volume and osmolal- 
ity measurements were made at times corresponding to venous blood sampling except for 10 minutes after the start of the operation.

\section{Study on Dogs}

Sixteen mongrel dogs of either sex weighing 6 to $13 \mathrm{~kg}$ were divided into two groups each of eight dogs; a low fluid load group $(10 \mathrm{ml} / \mathrm{kg} / \mathrm{hr})$ and a high fluid load group $(30 \mathrm{ml} / \mathrm{kg} / \mathrm{hr})$. All dogs were anaesthetized with thiopentone 20 to 25 $\mathrm{mg} / \mathrm{kg}$ intravenously, followed by tracheal intubation. Anaesthesia was maintained with nitrous oxide 70 per cent and oxygen 30 per cent. The mechanical ventilator (Aika Co. Ltd.) was set to maintain $\mathrm{Pa}_{\mathrm{CO}_{2}}$ at 4.6 to $5.3 \mathrm{kPa}(35$ to $40 \mathrm{~mm} \mathrm{Hg}$ ). A catheter was inserted into the right femoral artery to measure arterial blood pressure and to obtain blood samples. The left femoral vein was used for the administration of fluids. After obtaining a control blood sample, the infusion of lactated Ringer's solution was started at the rate appropriate to each group. Thereafter, laparotomy was done by a left flank incision. Elements of the heated thermocouple (Saneisokki needle type element) were inserted into the left renal cortex and the medulla. The amplified electrical output from the thermocouple equipment was connected with the recorder (Saneisokki Co. Ltd.). Intraperitoneal temperature was monitored by an electric thermometer (Saneisokki Co. Ltd.) and maintained at $38.3 \pm 0.5^{\circ} \mathrm{C}$ throughout the procedure.

Halothane anaesthesia combined with equal parts of nitrous oxide and oxygen was started when all these preparations were completed. Inspired halothane concentrations ranged from 1.0 to 2.0 per cent and were increased through this range in stepwise fashion, keeping each concentration for as long as $\mathbf{3 0}$ minutes. Measurement of renal tissue blood flow was made following the method described by Leighton, et $a .^{4}$ and Hirasawa. ${ }^{5}$

Blood and urine samples were obtained on six occasions from each dog; (1) immediately after tracheal intubation, (2) immediately before halothane anaesthesia, (3) after halothane 1 per cent for 30 minutes, (4) after 1.5 per cent for 30 minutes, (5) after 2 per cent for 30 minutes and (6) 30 minutes after the end of halothane anaesthesia, during which period pure oxygen was given After obtaining the last samples, the dog was sacrificed by intravenous injection of magnesium sulfate $5 \mathrm{~g}$. Renal tissue blood flow before halothane anaesthesia was defined as 100 per cent and as 0 per cent after death.
Plasma ADH was measured in a $2 \mathrm{ml}$ sample by radioimmunoassay according to the method of Husain, et al. ${ }^{6}$ Recovery rate was 73.9 per cent, coefficient of variation (c.v.) of the sample was 11 per cent and the minimum detecting range by this method was $1 \mu \mathrm{U} /$ tube, which indicates good reliability of the method. Serial electrocardiographic tracings and arterial blood gas analyses in both the clinical and dog experiments revealed no abnormalities throughout the procedure. The Student's $t$-test was used for statistical analysis.

\section{RESULTS}

\section{Clinical Study}

\section{Plasma ADH concentrations (Table I)}

The plasma concentration of ADH increased during anaesthesia alone in each group as compared with pre-induction level. It increased 3.7 times in the ether group, 2.4 times in the fentanyl group, 1.5 times in the thiopentone group, and 1.3 times in the halothane group. When compared with the controls, only the increases for ether and thiopentone were statistically significant. Superimposed surgical stress evoked significant elevation of $\mathrm{ADH}$ levels at 10 minutes after the skin incision, 3 to 7 times pre-induction levels, and this was followed by a gradual decline toward pre-induction levels. The slightly increased ADH level continued in the early post-operative period in each group.

\section{Urine output and osmolality (Table II)}

Reduction in urine output was observed during operation, but it was not statistically significant compared with values during anaesthesia alone in three of the groups, while in the ether group the value remained unchanged. However, a significant rise in urine output occurred when the patient had recovered from anaesthesia in the recovery room, although a wide variation was observed, the urine output ranging between 1.5 and 7.0 times the control level. Constant urine flow of 1,000 to $2,000 \mathrm{ml} /$ day continued in each group in the early post-operative period. Postoperative oliguria or anuria were not observed in any case. No appreciable change in serum osmolality was detected during anaesthesia and operation or early post-operatively in any group. Urine osmolality did not change remarkably during the operative day, but was followed by a marked decrease of 40 to 60 per cent on the first post. operative day. Thereafter it returned gradually to pre-induction levels. 

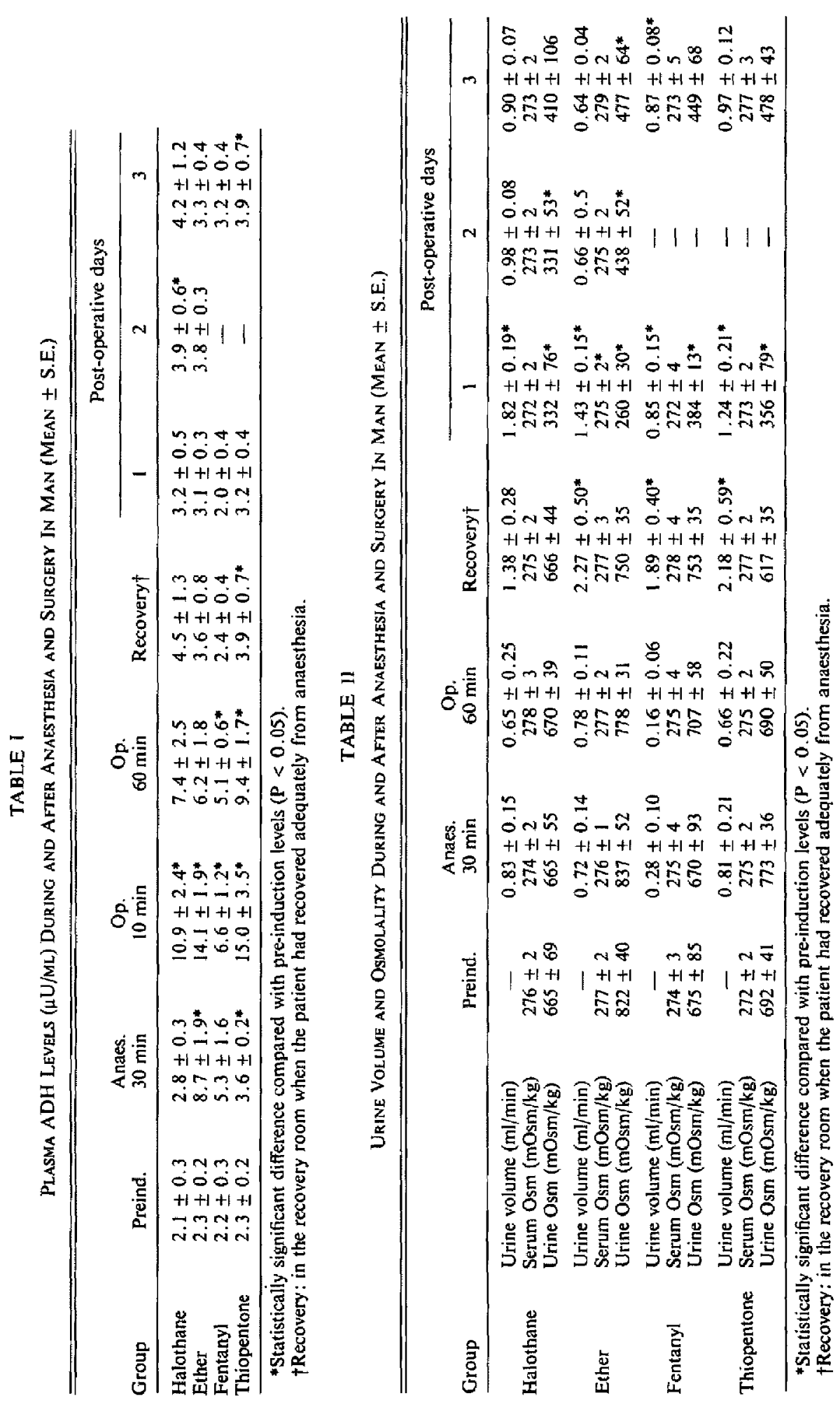


\section{Dog Experiments (Tables III and IV)}

\section{Plasma ADH concentrations}

A slight increase in plasma concentration of ADH compared with control levels was observed 30 minutes after the start of laparotomy under thiobarbitone anaesthesia in each group. In the low fluid load group, halothane anaesthesia increased the plasma concentration of $\mathrm{ADH}$ to 117 , 164 and 153 per cent of the control values during the inspired concentration of $1.0,1.5$ and 2.0 per cent respectively. These were statistically significant increases except for the value with 2.0 per cent halothane. In the high fluid load group, no significant changes were observed with any concentration of halothane.

\section{Renal Blood Flow}

Significant decrease in both cortical and medullary renal blood flow (RBF) was observed in the low fluid load group, though reduction in cortical RBF was more marked than the reduction in medullary flow. This was associated with significant decrease in mean arterial blood pressure. In the high fluid load group, the change in RBF was not evident, despite decreased mean arterial blood pressure with deepening inspired halothane concentration.

\section{Urine Output and Osmolality}

Urine output decreased significantly to $70 \mathrm{per}$ cent of control values after 30 minutes of halothane 2.0 per cent in the low fluid load group. However, no significant decrease was found in the high fluid load group as compared with control levels. In neither group were appreciable changes in serum osmollity observed throughout the procedure, although urine osmolality decreased gradually in both groups.

\section{Discussion}

The plasma concentration of antidiuretic hormone (ADH) is controlled mainly by ADH secretion from the posterior pituitary gland, metabolism in the liver and its excretion by the kidney. Of these factors, the secretion of ADH is the most important determinant of plasma concentration of the hormone.

Factors responsible for the release of $\mathrm{ADH}$ from the posterior pituitary gland during anaesthesia and surgery are stimulation of hypothalamic osmoreceptors by increased serum osmolality, stimulation of carotid baroreceptors by decreased arterial blood pressure and of volume receptors located in the left atrium which are sensitive to the reduced circulating blood volume. $^{7}$ Visceral $^{2}$ or vagal stimulation ${ }^{8}$ caused by surgical trauma, hypoxic or hypercapnic stresses, ${ }^{9}$ hormones including catecholamines and the renin-angiotensin system, ${ }^{7}$ and anaesthetic agents themselves are also considered to be operative factors. Several investigators, including the present authors, have demonstrated that anaesthetic agents stimulate ADH release..$^{10-12}$ Philbin, et al., ${ }^{13}$ however, could not find any increase in plasma ADH levels even after six hours exposure to light halothane anaesthesia $(0.4-0.5$ per cent inspired concentration) in dogs.

The present study showed that all four anaesthetic agents by themselves increased plasma $A D H$ levels in man; diethyl-ether was responsible for the greatest increase of plasma $A D H$ levels, while halothane caused the least. It is difficult to elucidate the possible causes for this difference in ADH stimulation by the several anaesthetic agents. One can say, however, that the difference appears to be quantitative rather than qualitative in nature.

Significant elevation in plasma ADH levels was found 10 minutes after skin incision in each group. This appeared to be caused by visceral stimulation, thus confirming previous reports. ${ }^{2,3}$ ADH levels remained elevated 60 minutes after the skin incision, but were lower than those at 10 minutes and this applied to each group. Two factors which might be responsible for this decline in $\mathrm{ADH}$ levels are that the period of visceral stimulation which elicited ADH release was transient and that the readily available pool of ADH for release from the pituitary gland, representing only 10 to 20 per cent of the total store of the hormone, ${ }^{14}$ had been discharged soon after the operation started.

Renal blood flow (RBF) and glomerular filtration rate (GFR), as well as ADH release are the important factors determining urine output. It is well established that anaesthetic agents including halothane, diethyl ether, thiopentone and fen. tanyl reduce RBF and GFR. ${ }^{15-17}$ Reduction in RBF during halothane anaesthesia correlated well with decreased arterial blood pressure, 5 although sustained autoregulation of RBF during halothane anaesthesia was recently documented in the isolated kidney of the $\operatorname{dog}^{8}$ A significant decrease in arterial blood pressure and renal tissue blood flow in both cortex and medulla was found in the low fluid load group, and this was associated with significant increase in plasma ADH level. On the other hand the values of both 

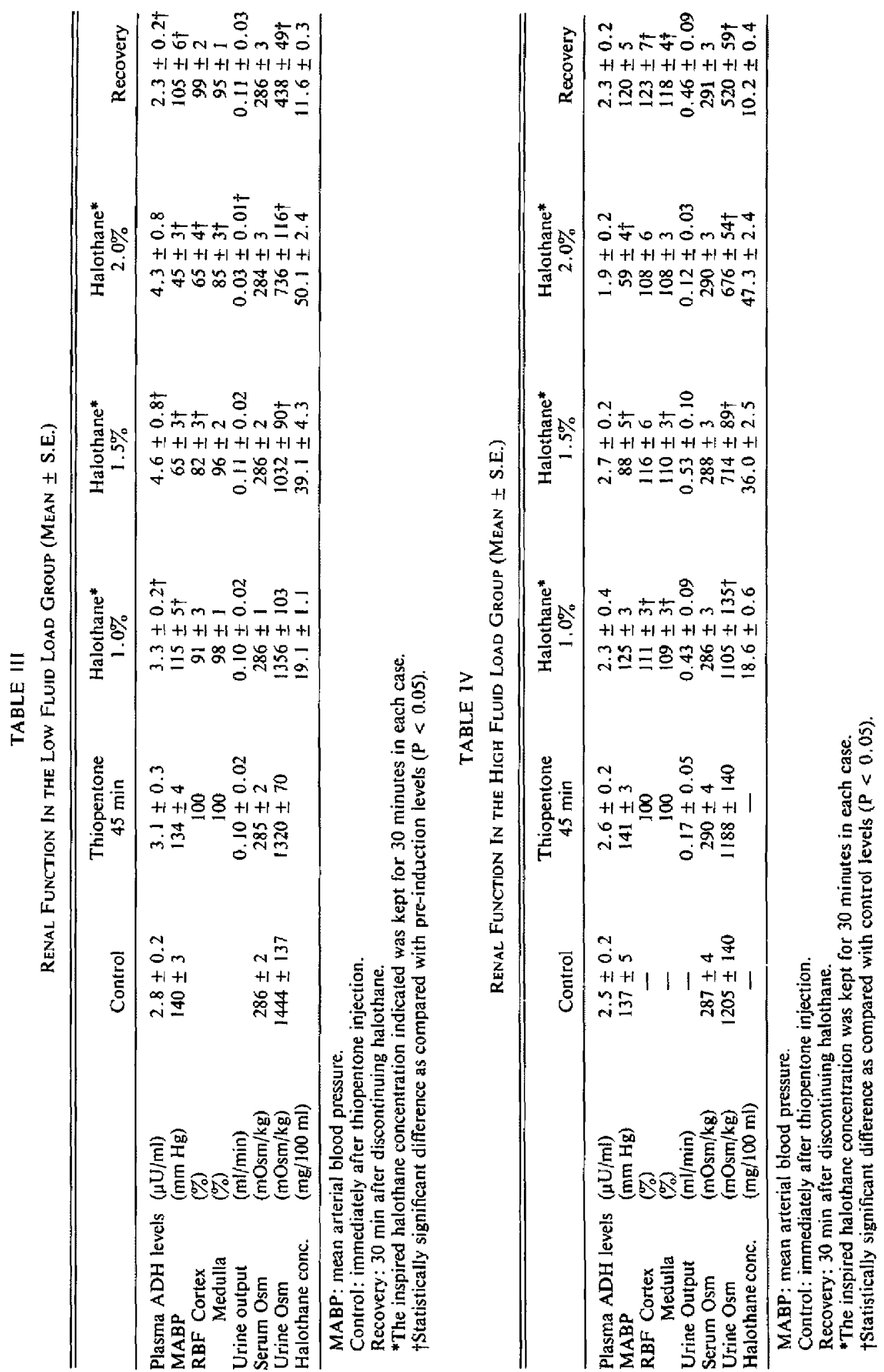
renal blood flows and plasma ADH did not correlate well with decreased arterial blood pressure in the high fluid load dogs as inspired halothane concentration increased. It is probable that these observations indicate that not only decreased arterial blood pressure but also the infused fluid volume might influence both renal blood flow and plasma ADH level, even after surgical trauma has been superimposed. Furthermore, the depth of anaesthesia might not always be the paramount determining factor in increase of plasma ADH levels.

Early in the post-operative period a slight increase in plasma ADH levels was still noted in each anaesthetic group in man. This would suggest that in the post-operative period the anaesthetic agent would be less responsible for release of $\mathrm{ADH}$ than other factors, including plasma volume deficit ${ }^{19}$ and the magnitude of the surgical stress. ${ }^{2,20}$

It is postulated that the volume of fluid administered modifies renal function during anaesthesia and surgery through changes in renal blood flow and by ADH release. Therefore administration of adequate amounts of fluid during anaesthesia is recommended, although excess fluid load must also be avoided due to the possiblility of precipitating post-operative pulmonary oedema.

\section{SUMMARY}

Plasma levels of antidiuretic hormone (ADH) were evaluated in 40 adult patients during and after various types of anaesthesia and surgery. The plasma level of ADH increased significantly 30 minutes after the start of anaesthesia with diethyl-ether (3.7 times) and after thiopentone (1.5 times), but it increased insignificantly in neuroleptanaesthesia (2.4 times) and with halothane (1.3 times). The surgical stress evoked marked increases in plasma ADH levels especially at ten minutes after the skin incision. A slight increase in plasma ADH level still continued into the early post-operative days.

The effects of halothane anaesthesia on plasma levels of ADH and on both cortical and medullary renal blood flow (RBF) were investigated in dogs. RBF was measured by means of a heated thermocouple in two groups of eight dogs each. One group was given a high fluid load of $30 \mathrm{ml} / \mathrm{kg} / \mathrm{hr}$ and the other a low load of $10 \mathrm{ml} / \mathrm{kg} / \mathrm{hr}$. The plasma level of ADH increased significantly with deepening halothane anaesthesia in the low fluid load group. However, in the high fluid load dogs it remained unchanged in spite of an increasing in- spired halothane concentration. Both cortical and medullary RBF fell significantly as compared with the control values in the low fluid load group. However, in the high fluid load dogs no significant decrease was observed. These results would indicate that the anaesthetic agents investigated in the present study caused increases in plasma ADH levels, but that these antidiuretic effects of anaesthesia might be modified by the volume of fluid infused during anaesthesia and operation.

\section{RÉSUMÉ}

Pendant et après la chirurgie sous différents agents anesthésiques, on a déterminé la concentration plasmatique de l'hormone antidiurétique (ADH) chez 40 patients adultes opérés pour des pathologies abdominales variées. Une augmentation significative de l'ADH a été notée après 30 minutes d'anesthésie à l'éther diéthylique (3.7 fois le contrôle) et le thiopentone ( 1.5 fois). Cette augmentation n'a pas été jugée significative après la neuroleptanesthésie ( 2.4 fois) et l'anesthésie à l'halothane ( 1.3 fois). Le stress chirurgical a provoqué une augmentation importante, surtout à la dixième minute après l'incision. Le niveau sanguin est demeuré légèrement élevé dans la période post-opératoire immédiate.

Les effets de l'anesthésie à l'halothane sur la concentration plasmatique de l'ADH et sur le flux sanguin rénal cortical et médullaire ont aussi fait l'objet d'une étude' chez le chien. Dans deux groupes de huit chiens, on a mesuré au thermocouple le flux sanguin rénal. Le premier groupe a reçu úne surcharge liquidienne de 30 $\mathrm{ml} / \mathrm{kg} / \mathrm{hre}$ alors que l'apport n'a été que de 10 $\mathrm{ml} / \mathrm{kg} / \mathrm{hre}$ pour le deuxième groupe. La concentration plasmatique d'ADH s'est élevée de façon significative dans le deuxième groupe. Toutefois, dans le premier groupe qui avait reçu le plus grand volume liquidien, le niveau plasmatique d'ADH n'a pas changé malgré les augmentations de concentration de l'halothane. Dans le groupe où l'apport liquidien a été le moins élevé, le flux sanguin cortical et le flux médullaire ont diminué de façon significative par comparaison aux valeurs de contrôle de ce groupe. Cette diminution n'a pas été notée pour le groupe surchargé. Ces résultats suggèrent que les agents anesthésiques utilisés dans cette étude augmentent le niveau d'ADH, mais que les effets antidiurétiques de l'anesthésie peuvent ètre modifiés par la quantité de liquide perfusée pendant l'anesthésie et l'opération. 


\section{REFERENCES}

1. Orama, T., Sato, K., \& Kimura, K. Plasma levels of anti-diuretic hormone in man during halothane anaesthesia and surgery. Canad. Anaesih. Soc. J. 18:614 (1971),

2. Moran, W.H., Miltenberger, F.W., Shuayb, W.A., \& ZiMMERMAN, B. The relationship of antidiuretic hormone secretion to surgical stress. Surgery 56: 99 (1964).

3. Ukai, M., Moran, W., \& Zimmerman, B. The role of visceral afferent pathways on vasopressin secretion and urinary secretory patterns during surgical stress. Ann. Surg. 168: 16(1968).

4. Leighton, K. \& Bruce, C. Distribution of kidney blood flow: a comparison of methoxyfurane and halothane effects as measured by heated thermocouple Canad. Anaesth. Soc. J. 22: 125 (1975).

5. Hirasawa, $\boldsymbol{H}$. Effects of ane sthetics on blood flow of the renal cortex and meduila. Jap. J. Anesth. 20: 539 (1971).

6. husain, M.K., Fernando, N., Shapjro, M., KAGAN, A., \& GLICK, S.M. Radioimmunoassay of arginine vasopressin in human plasma. J. Clin. Endocrinol Metab. 37: 616 (1973).

7. SCHREIER, R. \& BERL, T. Nonosmolar factors affecting renal water excretion. New Engl. J. Med. 292: 81 (1975).

8. Goetz, K.L., Bona, G.C., \& Bloxham, D.D. Atrial receptors and renal function. Physiol. Rev. 55: $157(1975)$

9. FORSLING, M.L. \& ReEs, M. Effects of hypoxia and hypercapnia on plasma vasopressin concentra. tion. J. Ëndocrinol. 67: 62P (1975).

10. DANIEL, A.R. \& LEDREIS, K. Effects of ether anesthesia and haemorrhage on hormone storage and ultrastructure of the rat neurohypophysis. J. Endocrinol. 34: 91 (1966).

11. Simpson, P, \& Forsling, M. The influence of halothane on plasma vasopressin concentrations during cardiopulmonary bypass. Brit. J. Anaesth. 48: 265 (1976).

12. Johnson, M.D. \& MALVin, R.L. Plasma renin activity during pentobarbital anesthesia and graded hemorrhage in dogs. Am. J. Physiol. 229: 1098 (1975).

13. Philbin, D.M., Baratz, R.A. \& Patterson, R.W. The effect of carbon dioxide on plasma antidiuretic hormone levels during intermittent positive-pressure breathing. Anesthesiology 33: 345 (1970).

14. Kurtzman, N.A.\& Boonjarern, S. Physiology of antidiuretic hormone and the interrelationship between the hormone and the kidney. Nephron 15: 167 (1975).

15. Miyazaki, M., Muranishi, Y., \& Yokono, S Anesthesia and renal function (Review article). Jap. J. Anesth. 26: 497 (1977)

16. Deutsch, S., Bastron, R.D., Peirce, E.C. Jr., \& VANDAM, L.D. The effects of anaesthesia with thiopentone, nitrous oxide, narcotics and neuromuscular blocking drugs on renal function in normal man. Brit. J. Anaesth. 4l: 807 (1969).

17. Gorman, H.M. \& Craythorne, N.W.B. The effects of a new neurolept-analgesic agent (Innovar) on renal function in man. Acta. Anaesth. Scand Supp. 24: 111 (1966).

18. Bastron, R.D., Perkins, F.M., \& Pyne, J.L. Autoregulation of renal blood flow during halothane anesthesia. Anesthesiology 46: 142 (1977).

19. Jenkins, M.T. The post-operative patient and his fluid and electrolyte requirements. Brit. J. Anaesth. 47: 143 (1975).

20. Sinnatamby, C., Edward, C.R.W., Kitau, M. \& IRVIN, M.H. Antidiuretic hormone response to high and conservative fluid regimes in patients undergoing operation. Surg. Gynecol. Obstet. 139: 715 (1974). 